\title{
IN SURINAME VOOR HONDERD JAAR
}

DOOR

\author{
MR. B. DE GAAY FORTMAN
}

W. L. Groeneveld Meyer geeft ter inleiding van een memorie van Van den Bosch over het oprichten eener bank voor onze West-Indische bezittingen in het E co n omisch historisch jaarboek, V. 1919 een beknopte schets van den toestand in Suriname in het eerste kwart der negentiende eeuw, om aan het slot daarvan aldus de uitzending van den commissaris-generaal te verklaren: „Talrijk waren dan ook de klachten en requesten aan den koning, en toen een ontslagen gouvernementssecretaris eene nota tot hem richtte, bevatte het stuk zooveel krasse en geargumenteerde beschuldigingen en grieven, dat men inzag, dat ingegrepen moest worden en werd de generaal van den Bosch als commissaris-generaal der West-Indische Bezittingen met vrijwel onbeperkte volmacht uitgezonden ,om den staat van zaken aldaar na te gaan en de noodige voorzieningen te doen plaatsgrijpen."

Hiervan nu is nagenoeg niets waar. Over de redenen, die tot de uitzending van Van den Bosch hebben geleid, hoop ik elders te schrijven - de beschuldigingen van Ringeling, den boven bedoelden ontslagen gouvernements-secretaris behooren daaronder niet. Wel werden deze hem nagezonden, en werd zijn opdracht met het onderzoek daarvan aangevuld. Kras waren zij ook, die beschuldigingen; over de argumenteering oordeele straks de lezer van dit opstel, want zij maken met Van den Bosch' onderzoek het onderwerp daarvan uit.

Hoewel Ringeling in Suriname zijn verzoekschriften aan den Koning door de drukpers heeft doen verspreiden 
in 500 exemplaren, is de inhoud ervan hier niet zeer bekend. Weinigen weten er meer van, dan wat Halberstadt ervan meedeelt, die ze noodig had voor zijn eigen zaak. Men kent die zaak wel. Halberstadt zelf heeft niet nagelaten haar telkens weer te bepleiten in zijn geschriften, die onder titels als Vrijmaking der slaven in Suriname en de opheffing van het meesterschap volgens de staatscommissie (1856) en Een standbeeld voor den Graaf Van den Bosch (1862) niet juist dezen inhoud doen vermoeden. Als eerste kommies bij de administratie van financiën te Paramaribo is Halberstadt eerst geschorst en daarna ontslagen, zooals hij zelf zegt, wegens het vervaardigen en uitdeelen aan eenige hoofdambtenaren op den nieuwjaarsdag van 1834 van papieren ridderorden en het bezigen van lasterlijke gezegden omtrent het Surinaamsche bewind en het bloot leggen van vijandelijke gezindheden in een particulieren brief. De toenmalige gouverneurgeneraal had hem dit aangedaan, en dezen overlaadt Halberstadt met de grofste beschuldigingen, ten deele ontleend aan Ringeling, terwijl hij ten onrechte Van den Bosch verwijt de benoeming tot gouverneur-generaal van den man, wiens tekortkomingen als fiskaal hij kende uit het onderzoek van Ringelings klachten.

Maar niet alleen Van Heeckeren was door den ontslagen Surinaamschen gouvernementssecretaris beschuldigd. De gouverneur De Veer, Ringelings schoonvader, was allerminst gespaard, en wat men in dezen als laakbare nalatigheid mocht willen vergoelijken, werd boos opzet in zijn zoon Casper Lodewijk de Veer, die op allerlei ongeoorloofde wijzen zou getracht hebben, zichzelf te verrijken. Een exemplaar der Surinaamsche uitgave van Ringelings verzoekschriften is aanwezig op de Koloniale bibliotheek in Den Haag.

Zijn beschuldigingen dienden om zijn verzoek tot rechtsen eerherstel na zijn ontslag kracht bij te zetten, en zelf was hij naar Nederland gereisd om bij den Koning en bij den minister voor de Marine en de Koloniën Elout zijn belangen mondeling voor te dragen. De eerste indruk dien beiden van zijn beschuldigingen gekregen hebben, 
zal wel dezelfde geweest zijn, als Groeneveld Meyer bijna honderd jaar later nòg had: Kras en geargumenteerd. Immers, wel werd hem aanstonds gelast, naar Suriname terug te keeren, maar dat was om tegenwoordig te zijn bij het onderzoek, dat Van den Bosch zou instellen naar zijn klachten over het hem aangedane onrecht en naar zijn aanklachten, en daarbij kreeg hij behalve vrije overtocht $f 600$. - voor uitrusting en het uitzicht op een door Van den Bosch te bepalen maandgeld, hangende het onderzoek. Wat zijn ontslag betreft, werd zelfs de beslissing in handen van den commissaris-generaal gelegd, „opdat, zoo dezelve ten voordeele van den suppliant was, hij dadelijk op de eene of andere wijze herstel van de hem toegebragte grieven zoude kunnen krijgen." Later, toen van opheffing van het ontslag geen sprake bleek te kunnen zijn, en de aanklachten tot haar ware verhouding waren teruggebracht, verontschuldigde de minister zich over de aanvankelijk tegemoetkomende houding, tegenover Ringeling aangenomen, met een beroep op „de min volledige ontwikkeling der gronden", waarop het ontslag besluit berustte; niet zonder reden, zooals men zien zal.

Wie was Ringeling? Jan Gerard Ringeling was Curaçaoenaar van geboorte. 2 Januari $1794 \mathrm{zag}$ hij het levenslicht. Nog onder het Engelsch bestuur was hij in 1815 ter algemeene secretarie op Curaçao werkzaam gesteld, om na den terugkeer van het Nederlandsche gezag in dien dienst bevestigd te worden. De Veer, zelf Curaçaoenaar, destijds gouverneur van St. Eustatius, Saba en St. Martin riep hem op 24-jarigen leeftijd als gouvernementssecretaris naar eerstgenoemd eiland, waar hij ook nog tal van andere betrekkingen, als auditeur-militair, fiskaal, ontvanger van de impost op de collaterale successie, bekleedde. En toen De Veer als gouverneur naar Suriname ging, in 1822, volgde hem zijn schoonzoon Ringeling. Secretaris van het Hof van politie en crimineele justitie, eerste commies ter gouvernements-secretarie en privé secretaris van den gouverneur, postmeester en havenmeester - in twee jaren tijds bekleedde hij al deze posten, 
en nam nog verschillende andere, als die van fiskaal, tijdelijk waar, om bij Koninklijk besluit van 6 Februari 1824 zich tot gouvernements-secretaris benoemd te zien.

Het is niet fraai wat wij na zijn ontslag van zijn ambtelijk en particulier leven te hooren krijgen: voortdurende afwezigheid van zijn bureau, knevelarij, schulden maken dronkenschap, tot zelfs op den sterfdag van een zijner kinderen, geweldpleging op zijn bedienden, mishandeling van zijn vrouw. En deze man beroemde er zich op, dat hij ouderling der Hervormde gemeente en grootmeester van de loge "Concordia" was. Een ernstige mishandeling van zijn vrouw in den nacht van 18 op 19 Januari 1827 , waaraan de gouverneur en de fiskaal te pas gekomen waren, om haar aan zijn handen te ontrukken, gaf den doorslag tot het ontslagbesluit, dat de gouverneur nam na raadpleging van- en in overeenstemming met zijn confidentieelen raad, waarin de fiskaal, de voorzitter van het Hof van civiele justitie en de raad-contrarolleur der financiën zitting hadden. Aan de regeering in het moederland deelde De Veer slechts mee, dat op grond van de nauwe betrekking tusschen hem en den ontslagene mocht worden aangenomen, dat voor het ontslag de grootste noodzakelijkheid bestond.

Die nauwe betrekking liep intusschen ten einde .Een tegen hem aangespannen echtscheidingsproces liet Ringeling in den steek, om in het moederland recht te gaan zoeken.

Welke waren zijn beschuldigingen? Ringeling heeft die, zooals reeds gezegd werd, laten drukken, en na zijn terugkeer te Paramaribo, 26 Maart 1828, daar verspreid, waarbij hij het deed voorkomen, alsof de Koning op hem een beroep gedaan had, om al die zaken eens tot klaarheid te brengen. De verzoekschriften van 31 October en 27 November 1827 aan den Koning bevatten in het kort de volgende aanklachten.

In 1822 waren door zekeren Beverley slaven in Martinique ingeladen met bestemming voor La Martinie, een koopman te Paramaribo. In plaats van die aldus af te leveren had kapitein Beverley hen in Nickerie geland 
en verkocht. Op verzoek van La Martinie bemoeide de fiskaal zich met de zaak met dit gevolg, dat de geadresseerde zijn slaven kreeg. Door toedoen van den Engelschen commissaris in het te Paramaribo gevestigde gemengde gerechtshof tot wering van den slavenhandel bepaalde de Koning echter, dat deze slaven alsnog moesten worden in vrijheid gesteld, daar zij oorspronkelijk te Martinique zouden zijn aangebracht van de kust van Guinea. In afwachting van hun terugkeer naar hun land moesten zij als vrije arbeiders ter beschikking van het gouvernement gesteld worden. Volgens Ringeling had nu ,de vindingrijkheid van den Raad Fiskaal, geruggesteund door de faciliteit van den Heer Gouverneur, het middel weten aan te wenden om, in plaats van de wezenlijk bedoelde slaven, anderen door ziekten en rampen uitgemergelde en vermagerde negers en negerinnen, uitschot van hospitalen en ziekenhuizen aan het Gouvernement over te leveren." En de beweegreden van deze handelwijs zou geweest zijn, dat de fiskaal anders afstand zou hebben moeten doen van de drie of vier slaven, die hij zelf van La Martinie verkregen had.

Den heer Van Heeckeren werd in de tweede plaats verweten zijn gedraging ten aanzien van de Afrikanen, die in 1821 met de Fransche brik la Legère waren aangebracht. Op vermoeden van verboden slavenhandel was dit schip aangehouden, en toen de bevoegde overheid teruggave van de lading aan de rechthebbenden bevolen had, zou de fiskaal getracht hebben eenige koppen achter te houden, wat door Ringeling zou zijn voorkomen.

Casper Lodewijk de Veer, des gouverneurs zoon, magazijnmeester in Suriname, als hoedanig zekere ambtenaar D. Schuurman voor hem ruimte zou hebben moeten maken, en vóór dien ontvanger van het klein zegel op St. Eustatius, werd beschuldigd, dat door zijn invloed op zijn vader deze in 1818 of 1819 als gouverneur van St. Eustatius een slavenschip ter reede van St. Martin, dat door zekeren Joly, commandore van een Venezolaansch eskader, als prijs opgevorderd werd, in diens handen was gespeeld, waarvan hij geldelijk voordeel zou hebben genoten. Als 
zegelbewaarder zou deze De Veer Jr. de slavenhandel of zeerooverij hebben bevorderd door 's lands zegels af te geven aan zekeren P. Brillenburg. Een van die aldus valschelijk gemaakte zeebrieven, waarop ook de handteekening van den gouverneur en van den secretaris T. G. Groebe voorkwam, zou in een geding op Curaçao overgelegd zijn. Des gouverneurs zoon Abraham de Veer Jr. zou bij die gelegenheid aldaar die handteekening van zijn vader voor valsch verklaard hebben, omdat er stond $A$. $d V e e r$ en niet $A$. de Veer, terwijl Ringeling nu aanvoert meer dan tien handteekeningen van zijn schoonvader zonder die $e$ te bezitten.

Als magazijnmeester had C. L. de Veer steekpenningen aangenomen van de leveringen aan het gouvernement tot $10 \%$ en meer van den prijs.

Het Nederlandsche garnizoen had slechts rum in plaats van jenever uitgedeeld gekregen.

Door bemiddeling van C. L. de Veer had de 2de luitenant R. H. Esser, met De Veers schoonzuster verloofd, den post van gouvernements-adjudant verkregen en de betrekking van commissaris voor de militaire zaken, die hem $f 6000$..- Sur. crt. opleverde, doch waarvoor hij de bekwaamheid miste, en die van havenmeester als belooning voor zijn optreden als curator van Ringelings vrouw in het echtscheidingsgeding.

Ook tegen de wijze, waarop hem ontslag was verleend had Ringeling allerlei bezwaren. Vooreerst waren de hem te laste gelegde feiten in strijd met waarheid. Hij was „met onvermoeiden ijver en ongeschonden probiteit werkzaam geweest, zonder dat hem immer eenig pligtverzuim is verweten geworden, of als nog te reprocheren zij." De gouverneur had slechts de bevoegdheid ambtenaren te schorsen, en hij was vóór het ontslag niet gehoord. Haat, drift en wraakzucht hadden den gouverneur, geleid tot diens besluit en van de confidentieele raden was de fiskaal met wraak jegens Ringeling bezield om diens tegenwerking in de zaak van de brik la Légère terwijl de voorzitter van het hof van civiele justitie en de raad-contrarolleur van financiën op de mededeelingen 
van den gouverneur afgegaan waren. In den nacht van 18 op 19 Januari 1827 was zijn huisrecht geschonden en de fiskaal had meegewerkt tot het weghalen van zijn vrouw en zuigend kind.

Voor zijn medewerking in de echtscheiding was de advocaat Mr. Presburg beloond met Ringelings post van gouvernements-solliciteur en met de waarneming van de betrekking van ontvanger der hoofdgelden.

Tot zoover de verzoekschriften van Ringeling aan den Koning.

Bij zijn aankomst in Suriname vond Van den Bosch, die eerst naar Curaçao en de bovenwindsche eilanden geweest was, een brief van Ringeling, die blijkbaar wilde voorkomen, dat inzonderheid Van Heeckeren den commissaris-generaal tegen hem innam. 'n Paar dagen later volgde een nieuw adres met nadere aanwijzing in zake de beschuldiging tegen den raad-fiskaal, voorzoover de door Beverley aangebrachte slaven betreft. De gouverneur, diens zoon Casper Lodewijk en de luitenant Esser volgden met uitvoerige weerleggingen van de openbaar gemaakte beschuldigingen van Ringeling.

Van den Bosch was ook niet te spreken over de gedragslijn, door den beschuldiger gevolgd. Zij had ten gevolge gehad, dat velen, die zich door fiskaal of gouverneur verongelijkt achtten, met klachten kwamen. De commissaris-generaal wilde de richting, waarin Ringeling hem trachtte te drijven - R. als openbaar aanklager, die den c.g. in staat stellen zou de beschuldigden te straffen - niet uit. Hem was opgedragen een nauwkeurig onderzoek naar Ringelings beschuldigingen in te stellen. Daartoe benoemde Van den Bosch 5 Mei 1828 een commissie, bestaande uit de heeren Mr. C. F. Mirandolle, L. B. Slengarde en Mr. P. Fiers Smeding, allen leden van het hof van civiele justitie, die als brave en onpartijdige menschen bekend stonden, in de beschuldigingen van Ringeling niet genoemd werden, terwijl twee hunner met verlof afwezig waren, toen de echtscheiding tusschen Ringeling en diens vrouw werd behandeld, en de daarbij voorgevallen omstandigheden plaats vonden. Wel heeft 
Ringeling nog een poging gedaan om Mr. Mirandolle te wraken, maar Van den Bosch wees dit kort en goed af.

Als eerste werd door de commissie de beschuldiger gehoord, op niet minder dan 99 vraagpunten. Voorts woonde hij de meeste verhooren der anderen bij, wier getuigenis hoofdzakelijk liep over de beschuldigingen tegen Van Heeckeren in zake de invrijheidstelling der slaven, door Beverley aangebracht, en het achterhouden van slaven van de brik la Legère, over de beschuldigingen tegen C. L. de Veer wegens het aannemen van steekpenningen en des gouverneurs medeweten hiervan, en over de gedragingen van Ringeling, die tot diens ontslag hadden geleid. Over de andere punten werden schriftelijke inlichtingen ingewonnen - o. a. moesten de leden van den confidentieelen raad zich verklaren over hun stem voor het ontslag van Ringeling en voorts werd gebruik gemaakt van de bij Van den Bosch ingekomen verweerschriften.

De beschuldigden zijn niet door de commissie gehoord. Van den Bosch had uitdrukkelijk bepaald, dat ,hooge autoriteiten of ambtenaren" alleen met zijn voorkennis en op zijn last inlichtingen zouden kunnen verstrekken, om den indruk te voorkomen, alsof zij als aangeklaagden voor hun rechters hadden te verschijnen. Eenerzijds moest voorkomen worden, dat zou kunnen gezegd worden, dat het gouvernement onverschillig was voor het gedrag zijner ambtenaren, maar anderzijds moesten deze ook gevrijwaard zijn voor voorbarige stappen en krenkende maatregelen van wege het gouvernement te hunnen aanzien.

Toen de commissie zoo ver met haar taak gereed was, dat zij op grond der getuigenverklaringen de beschuldiging tegen Van Heeckeren in zake de slaven van Beverley en die tegen den magazijnmeester De Veer over het aannemen van steekpenningen niet ongegrond achtte, werden de daarop betrekking hebbende stukken in handen der beschuldigden gesteld. Hun houding was weinig fraai. De Veer bleef ontkennen en wraakte alle bezwarende getuigenissen; Van Heeckeren gaf de feiten blijkbaar toe, maar hield vol van de verwisseling der slaven niets 
geweten te hebben. De antwoorden werden in handen der commissie gegeven, die bij haar verslag ook daarmee rekening hield.

Dit verslag bereikte Van den Bosch kort voor zijn vertrek uit Suriname, en het kwam neer op het volgende. De beschuldigingen tegen den oud-gouverneur De Veer waren gebleken van allen grond ontbloot te zijn. Ten aanzien van Mr. Van Heeckeren kwam de commissie tot een minder gunstige slotsom. Zij achtte bewezen, dat hij zich had schuldig gemaakt aan, ,het willens en wetens tolereeren, dat men illusoir heeft gemaakt het besluit van $Z$. M. den Koning, om de negers, door Kapitein Beverley aangebracht, aan het gouvernement over te geven en bij de vrije arbeiders te plaatsen, en zulks door gedachte negers te doen vervangen door andere, meest allen het voorkomen hebbende van ziekelijke gesteldheid, sommigen met de yawsziekte, anderen met booze zweren behebt, zulks om daardoor terug te kunnen houden en in het bezit te blijven van twee negerinnen, niettegenstaande hem bekend was, dat zij tot de bedoelde carga van Beverley behoorden". Van de vele beschuldigingen tegen den magazijnmeester C. L. de Veer was waar gebleken, dat hij van enkele leveranciers geld had aangenomen, dat hem intusschen niet door dwang of bedreiging maar vrijwillig en uit eigen beweging was toegelegd.

$\mathrm{Nu}$ kan men zeker zeggen, dat van de vele beschuldigingen van Ringeling er maar twee waren overgebleven, maar wat waar gebleken was, was dan toch ook nogal heel erg. Van den Bosch heeft niettemin gemeend het te moeten vergoelijken, vooral ten aanzien van Van Heeckeren. De commissaris-generaal vond wel, dat de gouverneur De Veer in de laatste jaren had blijk gegeven van eenige zwakheid in het belang zijner betrekking, en de noodige veerkracht had gemist, maar van kwade trouw was niet het minst gebleken, en daarom stelde Van den Bosch voor, dat hem van wege den Koning zou worden te kennen gegeven, dat hij van de aantijgingen van Ringeling volkomen gezuiverd was.

„Inderdaad laakbaar", dat was de hoogste veroor- 
deeling, waartoe Van den Bosch zich ten opzichte van Van Heeckeren kon opwerken. En dadelijk liet hij er op volgen, dat er verzachtende omstandigheden waren. Volgens de meening in Suriname was er geen aanleiding geweest, om de slaven van La Martinie vrij te laten, daar te hunnen aanzien de wetten op den slavenhandel niet overtreden waren, en voor La Martinie zelf zou de uitvoering van dien maatregel een groote hardheid zijn geweest. „Alle deze redenen”, aldus Van den Bosch, „,schijnen op de handelwijs van den heer Van Heeckeren een merkelijken invloed te hebben gehad, en de zucht om den heer La Martinie voor een totaal ongeluk te behoeden, en een maatregel, die men onbillijk geloofde, te ontduiken, heeft hem eene daad doen begaan, die, ik herhaal het, zeer laakbaar is en voor eenen ambtenaar hoogstens onvoorzigtig, maar die dan toch meer is toe te schrijven aan eene dwaling des verstands dan aan opzettelijken kwaden trouw en pligtverzuim." Wie dit leest, vertrouwt zijn oogen niet, die weinige regels te voren toch gezien hebben, dat Van den Bosch de commissie van onderzoek hoogelijk geprezen heeft om haar werk, en haar oordeel tot het zijne gemaakt, welke commissie toch uitdrukkelijke vastgesteld had, dat Van Heeckeren aldus gehandeld had, om in het bezit te blijven van zijn twee negerinnen. Ten slotte gaf een lofrede op Van Heeckerens bekwaamheden en ijver den commissarisgeneraal het voorstel in de pen, hem te berispen en te waarschuwen voor de toekomst ,met bijvoeging echter, dat $Z$. M. na de stipte uitvoering van den gegeven last de zaak wel zal willen houden voor afgedaan en niet gebeurd." De slaven van Beverley zouden dus nog moeten worden opgespoord en in vrijheid gesteld worden.

Ook voor C. L. de Veer wist Van den Bosch een verschooning aan te voeren, nl. ,dat zoodanig misbruik in de kolonien vrij algemeen scheen te wezen, en dat het over het algemeen niet als eene dadelijke malversatie wierd aangemerkt." Op dien grond stelde Van den Bosch voor, hem een ernstige berisping toe te dienen en in een andere betrekking te plaatsen. 
En eindelijk Ringeling. Ongetwijfeld kwam hij er het slechtste af. Wat zijn ontslag betreft, het was gebleken, dat hij zich van erger tot erger aan een ongeregelde levenswijs en aan buitensporige en schandelijke gedragingen had overgegeven, zoodat hij met geen mogelijkheid langer een openbare betrekking kon blijven bekleeden. Een slecht en zedeloos mensch, wordt hij door Van den Bosch genoemd, die, alleen door wraakzucht gedreven, vele menschen, waaronder degenen, aan wie hij alles verschuldigd was, in het ongeluk heeft zoeken te brengen door valsche en kwaadaardige aantijgingen. Van den Bosch, die zijn daggeld al had ingetrokken, stelde voor, hem als een gevaarlijk en rusteloos mensch het verblijf in de kolonie te ontzeggen, of wel bij wege van consideratie hem dat verblijf nog toe te staan - echter niet als inwoner - tot wederopzeggens onder voorwaarde, dat hij zich stil en ordelijk zou gedragen.

De minister, aan wien Van den Bosch verslag deed, was het in bijna alles met hem eens. Alleen ten aanzien vav de slaven van Beverley vond de minister beter, aan Van Heeckeren zonder meer in overweging te geven, de beide negerinnen in kwestie vrij te laten, en ten aanzien van Ringeling gaf de minister er de voorkeur aan, hem in Suriname te laten verblijven onder de door Van den Bosch voorgestelde voorwaarde. Of C. L. de Veer in een andere betrekking moest geplaatst worden, diende ter beoordeeling van den gouverneur-generaal te blijven.

Aldus geschiedde het. De Koning vereenigde zich met des ministers voorstel behalve ten opzichte van Van Heeckeren. Dezen moest worden te kennen gegeven, dat het den Koning zeer ongevallig geweest was te ontwaren, dat de bevelen met betrekking tot de slaven, door kapitein Beverley aangebracht, niet met nauwkeurigheid waren opgevolgd, en dat hij in zijn betrekking als raadfiskaal de flauwe uitvoering daarvan had gedoogd; dat echter uit aanmerking van de diensten, welke naar de berichten van den commissaris-generaal Van den Bosch door hem vroeger aan de kolonie waren bewezen, de Koning deze zaak ditmaal wel voor afgedaan wilde houden, 
doch hij tevens ernstig vermaand werd, om in het vervolg steeds met de meeste nauwkeurigheid de bevelen op te volgen, welke hem van wege het gouvernement van het Moederland zouden worden toegezonden.

Ringeling was inmiddels vertrokken naar de Vereenigde staten van Noord-Amerika.

Aan de commissie-leden werd 's Konings dank overgebracht voor den ijver en de strikte onpartijdigheid, waarmee zij hun moeielijke en teedere taak hadden volbracht.

Vóór het een half jaar verder was, kon Cantz'laar berichten, dat Van Heeckeren de negerinnen ter beschikking van het gouvernement had gesteld.

Wèl beschouwde de Koning de zaak voor afgedaan, want toen drie jaar later voor Cantz'laar een opvolger noodig was, werd Van Heeckeren benoemd tot gouverneur-generaal der Nederlandsche West-Indische bezittingen.

Amsterdam, 10 December 1928. 